\title{
BOTTLE CARIES AND DENTAL NEGLECT
}

\section{Sarah Raphael}

Specialist Paediatric Dentist and Visiting Dental Officer Westmead Centre for Oral Health

Each year large numbers of Australian children undergo dental treatment for bottle caries. This significant form of dental decay affects the first teeth of infants and young children who have, most often, been exposed to bottle feeding for long periods during each day and night. ${ }^{1,2} \mathrm{~A}$ recent study found that 40 per cent of decay in five-yearold Australian children remains untreated. ${ }^{3}$ Dental neglect is defined as the failure of a parent or guardian to seek, or follow through with, treatment for caries, oral infections or oral pain. As such, many children with bottle caries can be considered to be suffering from dental neglect. This article describes the prevalence of bottle caries, explores dental neglect, and concludes with simple preventive measures that can be used to protect the teeth of young children.

\section{BOTTLE CARIES}

Bottle caries is known by several different terms, including nursing caries, nursing bottle caries, baby bottle caries, and baby bottle tooth decay. Bottle caries is caused by the frequent and prolonged exposure of the teeth to a decay-causing substance, particularly at night when the cleansing effect of salivary flow is low. Such substances include human and cow milk, baby formula, sweetened milk, fruit juices, cordials and other soft drinks. Although bottle feeding is the most common cause, bottle caries can also result from the frequent use of a pacifier dipped in a sweetened substance, such as honey, and from prolonged on-demand breast feeding habits.

The pattern of decay that results from such practices is characteristic and affects, most severely, the upper primary incisor teeth and the primary first molar teeth, followed by the primary second molars and canines. This pattern of decay can be attributed to the eruption sequence of the primary dentition, whereby the first teeth to erupt have the longest exposure to the decay-causing habit. The primary lower incisor teeth are conspicuously spared from the decay process because of the position of the tongue during suckling and salivary secretion from the adjacent submandibular salivary gland ducts.

\section{PREVALENCE}

The reported prevalence of bottle caries in western countries of less than five per cent is probably underestimated because of the inaccessibility of the preschool population for dental examination. ${ }^{1,2}$ In addition, data collected may be from biased samples, as children whose parents are aware of an existing dental problem are more likely to present for examination. ${ }^{1,4}$ The available
Australian data reports prevalence figures ranging from 2.6 to 6.4 percent. $^{5-7}$ Studies of such groups of affected children have reported an association with low socioeconomic background, educational status, and age of the mother. ${ }^{8-10}$

Bottle caries is also thought to be a major cause of untreated dental decay in first teeth. A recent study found that 40 per cent of decay in five-year-old Australian children remains untreated. ${ }^{3}$ Although not all of this untreated decay can be attributed to bottle caries, it would be expected that a significant proportion of untreated caries in five-yearold children is associated with prolonged bottle or breast feeding habits. ${ }^{11}$

A recent study of patients referred for specialist paediatric dental services at Westmead Hospital Dental Clinical School has found that the most common outcome, accounting for 37 per cent of referred child patients, was treatment of dental decay under general anaesthetic. ${ }^{12} \mathrm{At}$ the same clinical school, more than 800 children per year receive a general anaesthetic for dental treatment, of which at least 80 per cent is for the management of decay. ${ }^{13}$ Of these children, 44 per cent are under three years old, strongly implicating bottle caries as a major cause. ${ }^{13}$

\section{DENTAL NEGLECT}

While in the process of developing policy documents of its own, the Australasian Academy of Paediatric Dentistry has adopted policies endorsed by the American Academy of Pediatric Dentistry. These American guidelines define dental neglect as the failure of a parent or guardian to seek treatment for caries, oral infection, or oral pain; or failure of the parent or guardian to follow through with treatment once informed that the aforementioned conditions exist. ${ }^{14}$ Figure 1 lists indicators of dental neglect in children. ${ }^{15}$ Both the first and third indicators can be associated with a significant number of children with bottle caries.

However, the situation is not as simple and straightforward as it seems. Generally, neglect can be defined as the failure of a parent or guardian to provide an adequate level of care unless the parent or guardian is unable to provide these needs for the child because of poverty ${ }^{16}$ Given that the parents of children with bottle caries are more often of low socioeconomic and educational status, it becomes more difficult to define children as suffering from dental neglect, as opposed to those whose parents or guardians are unable to access dental treatment due to socioeconomic and educational barriers.

Further, in spite of the fact that bottle caries most commonly affect the upper primary incisor teeth and are relatively easy to identify by lay people, parents or guardians often present late with children for consultation and treatment. 


\section{FIGURE 1}

\section{INDICATORS OF DENTAL NEGLECT IN CHILDREN ${ }^{15}$}

- Untreated, rampant caries that is easily detected by a lay person

- Untreated pain, infection, bleeding or trauma affecting the orofacial region

- History of lack of continuity of care in the presence of previously identified dental pathology

Unfortunately, once diagnosed, a small but significant group of children are not brought consistently for followup dental care. This group includes those children whose parents or guardians bring them for consultation and are informed of the child's dental condition and treatment needs, but do not follow through with subsequent treatment. It is children who fall into these categories, of presenting late for diagnosis or poor dental attendance, who can be identified as at risk of or suffering from dental neglect.

\section{PREVENTION}

Prevention of bottle caries requires appropriate dental education of new and prospective parents, including both dietary and oral hygiene advice. The use of the bottle as a pacifier should be discouraged and infants should not be allowed to fall asleep with a bottle containing decaycausing substances.

Once teeth appear, at around six months of age, they should be cleaned. Initially, this can be achieved by wiping the child's teeth and gums with a damp cloth, then aiming to introduce a small, soft toothbrush by 12 months of age. A smear of junior-strength toothpaste on the brush provides a regular fluoride treatment and should be used routinely from two years of age. Regular dental visits should begin around the child's first birthday to ensure early diagnosis and prevention.

The education and involvement of all maternal and child health professionals in preventing caries, including bottle caries, and in encouraging regular dental visits, is essential. Children's oral health must be regarded as an important component of their general health.

\section{REFERENCES}

1. Ripa LW. Nursing caries: A comprehensive review. Pediatr Dent 1988; 10: 268-82.

2. Yiu CK, Wei SH. Management of rampant caries in children. Quintessence Int 1992; 23: 159-68.

3. Slade GD, Spencer AJ, Davies MJ, et al. Influence of exposure to fluoridated water on socioeconomic inequalities in children's caries experience. Comm Dent Oral Epidemiol 1996; 24: 89100.

4. Kamp AA. Well baby dental examinations: A survey of preschool children's oral health. Pediatr Dent 1991; 13: 8690.

5. Calache H, Wright FAC. The dental status of four year olds in the Brunswick Child Development Study. Aust Dent $J$ 1989; 32: 126-31.

6. Brown JP, Junner C, Liew V. A study of Streptococcus mutans levels in both infants with bottle caries and their mothers. Aust Dent J 1985; 30: 96-8.

7. Wyne AH, Spencer AJ, Szuster FSP. Prevalence and risk factors of nursing caries in Adelaide pre-school children. $J$ Dent Res 1991; 70: Abstr 35.

8. Navia JM. Caries prevention in infants and young children: which aetiological factors should we address? (editorial) $J$ Pub Health Dent 1991; 54: 195-6.

9. Moynihan PJ, Holt RD. The national diet and nutritional survey of 1.5-4.5 old children: a summary of the findings of the dental survey. Br Dent $J$ 1996; 181: 328-32.

10. Johnson DC. The preschool passage: An overview of dental health. Dental care for the preschool child. Dent Clin North Am 1995; 39: 695-707.

11. O'Sullivan DM, Tinanoff N. Maxillary anterior caries associated with increased caries in other teeth. J Dent Res 1993; $72: 1577$.

12. Shah A. Utilisation of specialist paediatric dental services in Sydney. Sydney: University of Sydney, 1998, MSc thesis, in press.

13. Alcaino E. The pattern of usage of paediatric dental general anaesthetic services at Westmead Hospital, Sydney. University of Sydney, 1988, MDSc thesis, in press.

14. Pinkham JR. The practical importance of pediatric dentistry. In: Paediatric Dentistry - infancy through adolescence. 2nd Edition. Philadelphia: WB Saunders Co. 1994.

15. Loochtan RM. Dental neglect in children: definition, legal aspects and challenges. Pediatr Dent 1986; 8: 101-2.

16. Council Report. AMA diagnostic and treatment guidelines concerning child abuse and neglect. JAMA 1985; 254: 796-800. Fit 